\title{
CAUSAS E CONSEQUÊNCIAS DA CRIAÇÃO DE ENTIDADES AUTÔNOMAS
}

\author{
CAUSES AND CONSEQUENCES OF CREATING AUTONOMOUS ENTITIES
}

\author{
CAUSAS Y CONSECUENCIAS DE CREAR ENTIDADES AUTÓNOMAS
}

Bernardo Oliveira Buta *

\begin{abstract}
Resumo
A estrutura do Estado brasileiro conta com uma crescente criação de entes autônomos, o que inclui ministérios públicos, defensorias públicas, tribunais de contas, bem como a possibilidade de autonomia de outros órgãos, como o Banco Central, a Polícia Federal e a Advocacia-Geral da União. O presente ensaio lança proposições com o objetivo de jogar luz sobre as seguintes questões: por quais motivos os legisladores constituintes criam entes autônomos, independentes da estrutura de qualquer dos três poderes, alheios ao controle legislativo ou popular? Quais seriam as consequências da criação de tais entes? As respostas, em forma de proposições, abrangem a insegurança dos atores políticos quanto a situações futuras, o desempenho das políticas públicas, bem como a elevação dos custos de mudança de políticas e instituições.
\end{abstract}

Palavras-chave: Delegação; Entidades Autônomas; Governança.

\begin{abstract}
The structure of the Brazilian state has a growing creation of autonomous entities, which includes Public Prosecutors, Public Defenders' Offices, Courts of Auditors, as well as the possibility of autonomy of other bodies, such as the Central Bank, the Federal Police and the Federal Attorney General. This theoretical essay elaborates propositions in order to shed light on the following questions: Why do constituent legislators create autonomous entities, independent of the structure of any of the three State branches, unrelated to legislative or popular control? What would be the consequences of creating such entities? The answers, in the form of propositions, include the insecurity of political actors about future situations, the performance of the public policies, as well as the rising costs of changing policies and institutions.
\end{abstract}

Keywords: Delegation; Autonomous Entities; Governance.

*Defensoria Pública da União/Servidor Público. Fundação Getúlio Vargas/Aluno de doutorado. E-mail: bernardo.buta@gmail.com. ORCID iD: https://orcid.org/0000-0002-8936-3697. 


\section{Resumen}

La estructura del estado brasileño tiene una creación creciente de entidades autónomas, que incluye ministerios públicos, defensas públicas, tribunales de auditores, así como la posibilidad de autonomía de otros organismos, como el Banco Central, la Policía Federal y el Fiscal General Federal. Este ensayo teórico elabora proposiciones para arrojar luz sobre las siguientes preguntas: ¿Por qué los legisladores constituyentes crean entidades autónomas, independientes de la estructura de cualquiera de las tres ramas estatales, sin relación con el control legislativo o popular? ¿Cuáles serían las consecuencias de crear tales entidades? Las respuestas, en forma de proposiciones, incluyen la inseguridad de los actores políticos sobre situaciones futuras, el desempeño de las políticas públicas, así como los costos crecientes de cambiar políticas e instituciones.

Palabras clave: Delegación; Entidades autónomas; Gobernanza.

\section{Introdução}

A ordem constitucional vigente no Brasil estabelece, desde a origem, um Ministério Público dotado de autonomia administrativa, funcional, capacidade de elaborar a própria proposta orçamentária e de iniciar projetos de lei que disponham sobre a organização e funcionamento do órgão, bem como sobre a criação e extinção de seus cargos. Essa autonomia foi estendida às defensorias públicas estaduais, mediante a Emenda Constitucional n ${ }^{\circ} .45$, de 2004 e às defensorias públicas do Distrito Federal e da União, por meio das emendas constitucionais $\mathrm{n}^{\circ}$. 69, de 2012, e $\mathrm{n}^{\circ}$. 74, de 2013, respectivamente (BRASIL, 2004, 2012, 2013).

Além desses órgãos que orbitam o Judiciário, há atualmente algumas propostas de emenda à constituição (PEC) em tramitação na Câmara dos Deputados com o objetivo de converter órgãos públicos vinculados ao Poder Executivo em entes autônomos sem subordinação hierárquica a qualquer dos poderes da República. Destacam-se a PEC 82/2007, que visa atribuir autonomia e prerrogativas aos membros da Advocacia da União, Procuradoria da Fazenda Nacional, Procuradoria-Geral Federal, Procuradoria das autarquias e Procuradorias dos Estados, do Distrito Federal e dos Municípios (BRASIL, 2007a); a PEC 412/2009, que busca dotar a Polícia Federal de autonomia funcional, administrativa e de elaboração de proposta orçamentária (BRASIL, 2009); e a PEC 186/2007, que trata da autonomia órgãos de administração tributária da União, Estados, Distrito Federal e Municípios (BRASIL, 2007b).

Não é incomum haver entes autônomos na estrutura do Estado. Ao se observar a base de dados do Comparative Constitutions Project $^{1}$, destacam-se entes de controle de contas públicas, na figura de cortes ou conselhos de contas, ou ainda de auditores-gerais. Observam-se também bancos centrais, conselhos econômicos e comissões de serviço público. Esse modelo de organização dos entes públicos envolve uma solução de governança para a gestão das políticas a cabo desses entes. Trata-se de uma delegação na qual se transfere a autoridade dos órgãos representativos para instituições que não são administradas por políticos eleitos. Tal situação

\footnotetext{
${ }^{1}$ Informações retiradas da base de dados do Comparative Constitutions Project (COMPARATIVE, 2019). 
suscita as seguintes questões: por quais motivos os legisladores constituintes criam entes autônomos, independentes da estrutura de qualquer dos três poderes, alheios ao controle legislativo ou popular? Quais seriam as consequências da criação de tais entes?

No presente ensaio teórico, são elaboradas proposições como possíveis respostas a essas perguntas. Tais proposições são resultado de uma discussão teórica com diversos autores de uma literatura que abrange estruturas de governança democrática, envolvendo o constitucionalismo e a delegação de poderes a entes autônomos. O presente ensaio contribui com a literatura sobre o tema, uma vez que oferece uma via institucional para explicar as causas da delegação, que são majoritariamente explicadas com base nas expectativas dos atores políticos, bem como coloca luz sobre as consequências da delegação. Além disso, oferece uma ideia de operacionalização dessas proposições em futuras hipóteses de pesquisa empírica.

Além desta introdução, o texto contém outras três seções. A próxima seção trata das causas da criação de entes autônomos, em que são apresentadas duas proposições, discutidas nas subseções "Heterogeneidade de Atores", que traz a primeira proposição, e "Desempenho", onde está apresentada a segunda. Na seção seguinte, as proposições tratam de consequências da criação de entes autônomos, e estão apresentadas também em duas subseções "Modificação de Políticas Públicas" e "Ampliação dos Custos". A última seção do texto traz uma conclusão e uma proposta de agenda de pesquisa.

\section{Causas da criação de entes autônomos}

Entes autônomos podem ser conceituados como instituições estatais independentes cujos dirigentes não são diretamente eleitos pelo povo e às quais foi delegada autoridade em determinadas temáticas. A delegação é formalizada mediante um ato de direito público, no qual os representantes eleitos transferem a autoridade para os entes autônomos. Há uma relação principal-agente envolvida nessa delegação. Os principais, nesse caso, são os representantes eleitos, os quais criam os entes autônomos e lhes delegam poder e autoridade. Os agentes, por sua vez, são aqueles que exercem os poderes delegados, ou seja, a burocracia vinculada aos entes autônomos (SWEET; THATCHER, 2002).

As causas comumente citadas na literatura para motivar a delegação envolvem majoritariamente uma expectativa acerca dos resultados da delegação. Acredita-se que os entes autônomos atuariam de modo a aumentar a credibilidade do Estado no comprometimento com as políticas públicas (BACH, 2014). Estes entes autônomos, por terem menores possibilidades de interferência política, teriam uma atuação mais confiável (THATCHER, 2002). É esperado também que os funcionários desses entes autônomos desenvolvam e empreguem conhecimentos técnicos para a formulação e implementação das políticas públicas mais apropriadas, reduzindo assim a assimetria de informações (SWEET; THATCHER, 2002). Outro motivo seria o aumento de eficiência na resposta a problemas específicos, o que se funda na crença de que 
especialistas nas temáticas das políticas delegadas atuariam com maior eficiência do que políticos eleitos (VAN THIEL; YESILKAGIT, 2011; ECKERT, 2017). Por fim, outro motivo seria evitar levar a culpa por políticas impopulares (OVERMAN, 2016; ECKERT, 2017). Nesse caso, os representantes eleitos esperariam que os entes autônomos tomassem a culpa por políticas públicas impopulares, ou por eventuais erros na gestão das políticas públicas (SWEET; THATCHER, 2002).

Percebe-se que a literatura tem explicado as causas da delegação em função dos resultados esperados. Este estudo, no entanto, entende que as causas da delegação estão imbricadas no contexto institucional do sistema político, não apenas na expectativa dos representantes eleitos quanto aos resultados daquela delegação. Já no que se referem aos resultados esperados, as hipóteses lançadas na literatura podem ser resumidas em apenas uma: melhor desempenho das políticas públicas seja em termos de eficiência, eficácia ou efetividade.

\subsection{Heterogeneidade de atores}

Para tratar do contexto institucional do sistema político, é importante destacar o contraste entre democracias consensuais e majoritárias. Para tanto, Lijphart (1999) estabeleceu um modelo com duas dimensões, uma federativo-unitária e uma executivo-partidária. Por um lado, do ponto de vista da dimensão federativo-unitária, um sistema consensual caracterizar-seia por descentralização federativa; bicameralismo; rigidez constitucional; maior poder de revisão judicial; e independência do banco central. A partir da dimensão executivo-partidária, as características e um sistema consensual seriam: relação equilibrada entre os poderes Executivo e Legislativo; proporcionalidade na representação eleitoral; pluralismo dos grupos de interesse; maior número de partidos com representação no parlamento e com controle sobre os assentos legislativos (LIJPHART, 1999).

Por outro lado, um sistema majoritário, da perspectiva da dimensão federativo-unitária, estaria relacionado a estados unitários; unicamerais; com constituições menos rígidas; menor poder de revisão judicial; e com bancos centrais vinculados ao governo. No que se refere à dimensão executivo-partidária, um sistema político majoritário tenderia a apresentar dominância do Poder Executivo sobre o Legislativo; representação eleitoral majoritária; grupos de interesses corporativistas; bipartidarismo; e um menor grupo de partidos com assentos legislativos (LIJPHART, 1999).

Sistemas políticos consensuais possuem um maior número de atores e pontos de veto, o que tende a desacelerar o processo de tomada de decisões, além de torná-lo mais custoso (KNIGHT, 2001). Atores de veto são atores políticos capazes de exercer poder de veto sobre determinadas questões. Os pontos de veto, por sua vez, são os mecanismos institucionais utilizados por estes atores para vetar determinadas questões. O Judiciário, por exemplo, pode constituir um ponto de veto caso seja independente e dotado de poder para julgar a 
constitucionalidade da legislação promulgada (COX; MCCUBBINS, 2001). Nesse caso, os atores de veto são os entes capazes de provocar o Judiciário sobre as questões a serem vetadas.

Sistemas políticos com grande heterogeneidade de atores tendem a gerar incertezas quanto aos grupos que deterão o controle decisório no futuro. Ou seja, é factível que, havendo uma maior quantidade de grupos de interesse capazes de influenciar a tomada de decisões, não haja grupos hegemônicos por grandes períodos de tempo. Considerando essa incerteza, é possível acreditar que os atores dominantes no presente se colocam avessos ao risco, optando assim por desenhar instituições consensuais (contramajoritárias) para fazer valer seus interesses, o que abarca regras mais rígidas para emendar a constituição, dispositivos constitucionais mais detalhados, delegação de maior poder à corte constitucional e possibilidade de um maior número de atores provocarem essa corte (KNIGHT, 2001).

Por conseguinte, os sistemas políticos consensuais podem ser decorrentes de contextos em que há grande heterogeneidade de atores políticos. Nesse sentido, instituições de compartilhamento de poder tendem a ser mais resilientes do que instituições de concentração de poder. Uma vez criadas, as instituições pluralistas não enfrentam as mesmas pressões para mudanças do que as instituições majoritárias; pois, ao longo do tempo, encorajam o surgimento de um maior número de atores com interesse em sua manutenção (NEGRETTO, 2012). É possível inferir, portanto, que sistemas políticos amplamente consensuais e com grande heterogeneidade de atores fazem parte de um ciclo vicioso, no qual uma conjuntura constituinte em que há diversos grupos de interesse capazes de influenciar a tomada de decisão cria um sistema político consensual que, por sua vez, estimula o surgimento de mais atores capazes de vetar as decisões, o que retroalimenta a circunstância inicial. Exemplo disso tem sido a ampliação da quantidade de partidos políticos ao longo do período democrático no Brasil, bem como a ampliação de atores capazes de questionar a constitucionalidade das leis perante o Supremo Tribunal Federal (RODRIGUES, 2019).

Dessa feita, eis a primeira proposição acerca dos motivos de criação de entes autônomos:

Proposição 1: Processos constituintes permeados por heterogeneidade de atores influenciam a criação de novos atores e pontos de veto.

A incerteza política foi colocada por Elgie (2006) como possível causa para delegações. Contudo, o autor entende que a incerteza é inerente à democracia, e não relaciona esse fator ao tipo de sistema político. De fato, sempre haverá incerteza em relação ao futuro. No entanto, os argumentos aqui colocados são os de que há maior incerteza em sistemas políticos consensuais devido à heterogeneidade de atores e quantidade de pontos de veto. Ressalta-se também que a incerteza não é a variável independente da relação disposta na Proposição 1, mas o mecanismo que explicaria a correlação entre a heterogeneidade de atores e a criação de novos atores e pontos de vetos via delegação. 


\subsection{Desempenho}

Considerando a maior quantidade de atores e interesses envolvidos nas tomadas de decisões em sistemas políticos consensuais, é forçoso considerar o custo de transação envolvido na coordenação desses atores para se atingir o consenso. Esses custos aumentam exponencialmente à medida que se ampliam os atores relevantes envolvidos (HOOGHE; MARKS, 2003). Desse modo, depreende-se que há maior dificuldade na formulação e modificação de políticas públicas em sistemas consensuais. Escolhas por determinados desenhos institucionais, além de levar em conta os benefícios que determinadas regras constitucionais podem prover, também considerariam interesses comuns no desempenho eficiente dessas instituições (COX; MCCUBBINS, 2001; NEGRETTO, 2013)

Assim, a criação de entes autônomos em Estados com sistemas políticos consensuais poderia seguir duas lógicas distintas, mas complementares. Por um lado, seguiria uma lógica cooperativa, com o interesse comum de que as políticas estabelecidas constitucionalmente sejam efetivas. Por outro, haveria uma lógica de poder, considerando os benefícios políticos a determinados grupos com a criação de instituições autônomas (NEGRETTO, 2013). Assim, do ponto de vista cooperativo, entes autônomos resultariam em políticas públicas mais efetivas. Já do ponto de vista de poder, alguns atores ganhariam mais com a autonomia, com destaque para interesses particulares ou de determinados grupos.

Como reforço à lógica cooperativa, é forçoso destacar a deterioração da legitimidade do Estado para a realização de políticas públicas desde o final do século passado. Atores estatais são vistos, muitas vezes, como lentos e burocráticos. As teorias de governança e da nova gestão pública consolidam a ideia de que a administração pública isolou-se do restante da sociedade e das pressões econômicas, o que resultou em uma administração pública negligente e ineficaz (PETERS; PIERRE, 1998). Nessa perspectiva de descrédito das instituições democráticas, é possível acreditar que funções que não poderiam ser delegadas ao setor privado tenderiam a ser mais bem realizadas por entes autônomos, insulados das disputas políticas e menos controlados. Além disso, políticas públicas complexas tenderiam a ser mais bem executadas por burocracias especializadas e dotadas dos recursos necessários para sua execução (VAN THIEL; YESILKAGIT, 2011; ECKERT, 2017).

Na prática, é possível pensar que o povo desejaria construir instituições insuladas e com maior nível de capacidade técnica. Seguindo essa lógica, um bom nível de insulamento poderia assegurar que as instituições apresentem, ao longo do tempo, os resultados que o povo deseja (FEREJOHN, 2002). Ou seja, a escolha pela criação de entes autônomos insulados seria definida com base nos resultados esperados.

Além disso, instituições autônomas podem funcionar como mecanismos de governança do Estado. O Ministério Público, por exemplo, é o responsável por acionar o Judiciário quando políticas púbicas não são executadas efetivamente. A Defensoria Pública possui um papel 
semelhante, mas com foco nos cidadãos vulneráveis. Os tribunais de contas, por sua vez, são os responsáveis pelo controle das contas públicas nos diversos níveis federativos. Nesse sentido, tais instituições são necessárias para que a delegação da execução de leis feita pelos poderes Executivo e Legislativo não se torne uma renúncia à responsabilidade desses poderes.

Há, portanto, a separação do poder entre diversos atores com propósitos distintos. Ao delegar poder a atores com ambições contrárias, intenta-se estimular que esses atores regulemse uns aos outros, prevenindo que tomem vantagem do poder que lhes foi delegado (COX; MCCUBBINS, 2001). Nesse sentido, a criação de entes autônomos estaria ligada a um maior nível de governança do Estado e, consequentemente, melhor desempenho das políticas públicas, o que leva à proposição seguinte:

Proposição 2: A criação de entes autônomos buscaria garantir o melhor desempenho das políticas públicas determinadas constitucionalmente.

Ressalta-se que esta é uma hipótese relacionada à expectativa dos representantes eleitos quanto aos resultados das políticas públicas após a delegação para entes autônomos. Ou seja, a delegação ocorreria por uma expectativa de melhor desempenho, o que não necessariamente pode representar uma efetiva melhora no desempenho das políticas públicas delegadas. Sobre o assunto, vale destacar que a substituição dos critérios políticos para a seleção das lideranças por critérios baseados no mérito, que ocorre em larga medida quando se tratam de entes autônomos, pode acarretar em menor responsividade aos anseios políticos, prejudicando a correspondência entre os resultados eleitorais e as políticas públicas. Com menor consonância entre as metas políticas e a gestão das políticas, o desempenho consequentemente será menor, tendo em vista que os critérios para avaliação se modificam a partir da mudança de preferência política. Ademais, o processo de reforma administrativa tendeu a remover os controles sobre as burocracias, o que vem se intensificando com o estabelecimento de entes públicos autônomos. Esse tipo de mudança enfraquece os sistemas de responsabilização, podendo acarretar perda de desempenho (PETERS; PIERRE, 2004).

\section{Consequências da criação de entes autônomos}

\subsection{Modificação de Políticas Públicas}

Um sistema político com múltiplos pontos e atores de veto pode levar a duas situações distintas. Por um lado, a fragmentação do sistema político combinando monitoramento independente e mecanismos de coação do cumprimento das leis pode ser capaz de limitar a corrupção. Por outro lado, muitos pontos de veto podem tornar o sistema político suscetível ao enriquecimento dos atores com poder de veto à custa dos recursos públicos (ROSEACKERMAN, 1999).

No primeiro ponto, destaca-se que a criação de entes autônomos pode funcionar como um mecanismo de governança do Estado, prevenindo desvios. Os entes criados com ambições 
contramajoritárias funcionam como um ponto de controle independente. Exemplos disso podem ser as Cortes de Contas, os Ministérios Públicos ou até mesmo a Corte Constitucional. Segundo Cox e McCubbins (2001), busca-se não só a separação de poderes, mas o estabelecimento de regras que garantam as agências importantes não sejam controladas por um único interesse.

Já no que se refere ao segundo ponto, a criação de entes autônomos amplia a quantidade de atores com poder de veto no processo de tomada de decisões, acarretando elevação dos custos de transação para se atingir o consenso necessário à formulação ou modificação de políticas. Isso ocasiona maior dificuldade de mudança nas políticas públicas, porém maior comprometimento com as políticas já adotadas (COX; MCCUBBINS, 2001). De fato, múltiplas fontes de autoridade conferem maior vantagem ao status quo, pois implica que nenhum grupo possua poder absoluto. Ao menos que haja acordo entre os entes com poder de veto, nada poderá ser feito (ROSE-ACKERMAN, 1999).

Embora este raciocínio seja intuitivo, Negretto (2012) sugere que as constituições de países com sistemas partidários fragmentados (onde há muitos partidos políticos com representação no parlamento), quando rígidas, possuem maiores taxas de substituição, e quando flexíveis, possuem maiores taxas de emendamento (NEGRETTO, 2012). Isso indica uma maior competição pelas regras do jogo em sistemas políticos consensuais, o que tenderia a agir de modo contrário ao raciocínio anterior. Ou seja, ao invez de preservar o status quo, os sistemas consensuais levariam a mudanças mais frequentes nas regras do jogo.

Há, nesse caso, dois possíveis resultados opostos. Por um lado, haveria um maior número de atores interessados na manutenção das regras do jogo e nas políticas públicas que os beneficiam. Por outro, a maior quantidade de atores tenderia a ampliar a competição política, pressionando a mutação constante das regras do jogo e das políticas públicas de acordo com o grupo que domina a tomada de decisões em determinados momentos. No entanto, é necessário colocar que o que definiria tais resultados não é apenas a quantidade de atores, mas sua heterogeneidade. Ou seja, atores políticos com interesses conflitantes induziriam a mudança. Já atores políticos com interesses similares geraria estabilidade. Contudo, os atores de veto são criados com objetivo de separação entre poder e propósito (COX; MCCUBBINS, 2001). Isto é, estes atores já nasceriam com propósitos contramajoritários, o que leva à proposição seguinte:

Proposição 3: Uma maior quantidade de entes autônomos acarreta maiores taxas de emendamento constitucional e de modificação de políticas públicas.

Há, no entanto, uma ressalva que precisa ser feita. As modificações constitucionais não devem abranger todo e qualquer dispositivo. Vale lembrar que é interesse dos atores políticos manterem os fundamentos do sistema que os criou e os permite sobreviver. Conforme colocam Arantes e Couto (2012), o processo de emendamento constitucional tende a ser mais intenso em constituições que possuem grandes quantidades de políticas públicas, como é o caso da brasileira. Em casos assim, o governo é estimulado a modificar a Constituição para 
simplesmente poder implementar sua agenda política, o que aumenta os custos da formulação de políticas públicas (ARANTES; COUTO, 2012).

\subsection{Ampliação dos Custos}

A ampliação da quantidade de entes autônomos gera também uma situação em que, com uma maior quantidade de atores capazes de fazer valer seus interesses, as políticas públicas tenderiam a atender a interesses privados, ou de grupos específicos (ROSE-ACKERMAN, 1999; COX; MCCUBBINS, 2001; TOMIC, 2018). Isso ocorreria como uma consequência da barganha política entre os atores com poder de veto, uma vez que cada um desses atores é capaz de demandar pagamentos paralelos (COX; MCCUBBINS, 2001), mesmo que na forma de emendas a políticas públicas, ou recursos voltados para seu eleitorado.

Somado a isso, cumpre frisar que o grau mais apropriado de autonomia não permite que burocratas se isolem da sociedade ao ponto de tomar decisões em desacordo com as demandas sociais. Contextos de grande autonomia, nos quais a burocracia escapa do controle político, tendem gerar baixos níveis de desempenho (FUKUYAMA, 2013). Ou seja, apesar do sentimento de que a criação de entes autônomos provocaria melhores resultados, o desequilíbrio entre autonomia e controle poderia conduzir a um pior desempenho.

Vale destacar que a representatividade carrega consigo valores significativos para uma sociedade democrática. Um serviço público representativo tende a ser mais aberto e acessível ao cidadão comum, o que ocasiona maior igualdade de oportunidades (MOSHER, 1968). Nos moldes como têm sido criados no Brasil, os entes autônomos são insulados da sociedade e alheios ao controle democrático. Nesse caso, os agentes tomadores de decisão estão distantes do povo e de seus representantes diretos, ou seja, não são eleitos tampouco nomeados abertamente por representantes eleitos, mas são escolhidos com base em critérios estabelecidos que restringem fortemente a decisão da autoridade que os nomeia ${ }^{2}$.

Sobre o assunto, é importante destacar ainda que o monitoramento direto e ativo dos entes autônomos pelo Legislativo, além de ser custoso, não gera benefícios eleitorais. Assim, os legisladores optam por uma supervisão mais distante, esperando por sinais de que esses entes autônomos estão executando de forma inadequada as políticas delegadas. Isso permite aos políticos se atentar para as questões que importam mais para os seus eleitores e reivindicar crédito pelos problemas resolvidos (LUPIA; MCCUBBINS, 2000). Em suma, o sistema de controle do Legislativo sobre entes autônomos requer a atenção dos legisladores apenas quando há um problema substantivo (WEINGAST, 1984).

\footnotetext{
2 Exemplo disso pode ser visto na Lei Complementar 80/1994, que organiza a Defensoria Pública. O chefe da instituição é nomeado pelo Chefe do Poder Executivo dentre os defensores arrolados em uma lista tríplice formada pelo voto dos demais integrantes da carreira de defensor público.
} 
Nesse sentido, ao considerar que os indivíduos tendem a ser oportunistas e auto interessados, a burocracia vinculada a entes autônomos, distantes do controle democrático, tenderia a utilizar o poder que lhe fora delegado em benefício próprio, o que induziria comportamento fisiológico e consequentemente maiores custos com sua manutenção. Os gestores de entes autônomos tenderiam a manter as políticas públicas funcionando em um nível de eficiência sub ótimo, de modo que consigam maximizar seus interesses e minimizar os riscos de sanções (TOMIC, 2018), fazendo valer suas próprias agendas de afirmação institucional (ARANTES; MOREIRA, 2019). Daí a proposição seguinte:

Proposição 4: Entes autônomos acarretam maiores custos para o Estado.

Isso tenderia a ser ainda mais relevante nos casos em que a criação de entes autônomos envolve uma delegação de poder muito ampla, de modo que os representantes eleitos perdem o controle sobre os burocratas. Nesses casos, a delegação passa a ser abdicação (LUPIA; MCCUBBINS, 2000). Essa incapacidade de controle permite que os agentes tomem decisões que maximizem seus interesses, envolvendo não apenas benefícios pecuniários, como também benefícios decorrentes de aspectos não pecuniários, por exemplo, luxo nas instalações físicas do local de trabalho e baixo nível de disciplina dos agentes (JENSEN; MECKLING, 2008).

\section{Conclusão}

O presente ensaio teórico teve por objetivo elaborar proposições acerca dos motivos que levam os legisladores constituintes a criar entes autônomos alheios ao controle legislativo ou popular, bem como as consequências da criação desses entes. Destaca-se que as quatro proposições apresentadas não trazem um rol exaustivo de possíveis respostas às questões inicias, mas são uma tentativa de colocar luz sobre o fenômeno atual da criação de entes autônomos.

As proposições baseiam-se no pressuposto de que sistemas políticos consensuais são permeados por grande quantidade de atores políticos com interesses diversos. No que se refere aos motivos pelos quais os legisladores criam entes autônomos, argumenta-se que a heterogeneidade de atores políticos envolvidos nos processos constituintes gera incerteza quanto aos grupos políticos hegemônicos no futuro, o que incentiva a criação de instituições consensuais. Tais instituições também incentivam a criação de novos atores políticos, em um ciclo vicioso, ampliando a quantidade de entes autônomos. A proposição colocada inicialmente parte da premissa de que a principal causa da criação de entes autônomos está justamente nas instituições que definem o funcionamento do sistema político: 1) Processos constituintes permeados por heterogeneidade de atores influenciam a criação de novos atores e pontos de veto.

Como consequência da heterogeneidade de atores e interesses, está a maior lentidão no processo de tomada de decisões e os maiores custos envolvidos na formação de consenso para 
tais decisões. Somado a isso, a deterioração da legitimidade do Estado e a necessidade de políticas públicas mais efetivas tornam possível inferir que a criação de entes autônomos buscaria garantir o melhor desempenho das políticas públicas determinadas constitucionalmente, Proposição 2.

As Proposições 3 e 4 são relacionadas às consequências da criação de entes autônomos. A argumentação considera que a maior heterogeneidade de atores políticos envolvidos na tomada de decisão ocasiona um maior nível de conflito e em maiores custos de transação para consecução de consenso. Assim, as proposições colocadas são: 3) uma maior quantidade de entes autônomos acarreta menores taxas de emendamento constitucional e de modificação de políticas públicas; e 4) entes autônomos acarretam maiores custos para o Estado.

Seriam necessários estudos empíricos para testar tais proposições. Para tanto, a base de dados do Comparative Constitutions Project pode ser de grande valia, uma vez que dispõe de grande quantidade de variáveis acerca de inúmeras constituições em vigor ou já suplantadas. Especificamente no que se refere aos entes autônomos, a referida base dispõe de informações preciosas acerca da existência de entes com autonomia determinada constitucionalmente.

Algumas proposições poderiam ser endereçadas mediante estudos quantitativos. A primeira proposição, por exemplo, poderia ser confirmada mediante um estudo que correlacionasse a quantidade de partidos políticos no Congresso com a quantidade de entes autônomos. A terceira proposição poderia ser testada mediante a correlação entre a quantidade de entes autônomos e a taxa de emendamento constitucional. Já na quarta proposição, seria interessante correlacionar os dados sobre a quantidade de entes autônomos e os gastos do governo de cada país. A segunda proposição, por sua vez, poderia ser testada por meio de análises qualitativas das motivações elencadas pelos parlamentares nas propostas de emenda constitucional ou nas seções em que estas propostas foram deliberadas. 


\section{Referências}

ARANTES, R. B.; COUTO, C. G. Constitutionalizing Policy: The Brazilian Constitution of 1988 and its Impact on Governance. In: NOLTE, D.; SCHILLING-VACAFLOR, A. New Constitutionalism in Latin America: promises and practices. Farnham: Ashgate Publishing, 2012. p. 203-222.

ARANTES, R. B.; MOREIRA, T. M. Q. Democracia, instituições de controle e justiça sob a ótica do pluralismo estatal. Opinião Pública, Campinas, v. 25, n. 1, p. 97-135, 2019.

Disponível em: http://www.scielo.br/scielo.php?script=sci_arttext\&pid=S0104$62762019000100097 \&$ tlng=pt. Acesso em: 4 jun. 2019.

$\mathrm{BACH}, \mathrm{T}$. The autonomy of government agencies in Germany and Norway: explaining variation in management autonomy across countries and agencies. International Review of Administrative Sciences, v. 80, n. 2, p. 341-361 , 2014. Disponível em: https://journals.sagepub.com/doi/10.1177/0020852313514527. Acesso em: 4 jun. 2019.

BRASIL. Câmara dos Deputados. Proposta de Emenda à Constituição n ${ }^{\circ} 82$ de 2007. Acresce os arts. 132-A e 135-A e altera o art. 168 da Constituição Federal. Brasília: Câmara dos Deputados, 2007a. Disponível em:

https://www.camara.leg.br/proposicoesWeb/fichadetramitacao?idProposicao=354302. Acesso em: 4 jun. 2019.

BRASIL. Câmara dos Deputados. Proposta de Emenda à Constituição n 186 de 2007. Acrescenta os $\S 13$ e 14 ao art. 37 da Constituição Federal. Brasília: Câmara dos Deputados, 2007b. Disponível em:

https://www.camara.leg.br/proposicoesWeb/fichadetramitacao?idProposicao=375821. Acesso em: 4 jun. 2019.

BRASIL. Câmara dos Deputados. Proposta de Emenda à Constituição n ${ }^{\circ} 412$ de 2009. Altera o $\S 1^{\circ}$ do art. 144 da Constituição Federal, dispondo sobre a organização da Polícia Federal. Brasília: Câmara dos Deputados, 2009. Disponível em:

https://www.camara.leg.br/proposicoesWeb/fichadetramitacao?idProposicao=453251. Acesso em: 4 jun. 2019.

BRASIL. Emenda à Constituição ${ }^{\circ} 45$ de 2004. Altera dispositivos dos arts. $5^{\circ}, 36,52,92$, 93, 95, 98, 99, 102, 103, 104, 105, 107, 109, 111, 112, 114, 115, 125, 126, 127, 128, 129, 134 e 168 da Constituição Federal, e acrescenta os arts. 103-A, 103B, 111-A e 130-A, e dá outras providências. Brasília: Câmara dos Deputados, 2004. Disponível em:

http://www.planalto.gov.br/ccivil_03/constituicao/emendas/emc/emc45.htm. Acesso em: 4 jun. 2019.

BRASIL. Emenda à Constituição n ${ }^{\circ} 69$ de 2012. Altera os arts. 21, 22 e 48 da Constituição Federal, para transferir da União para o Distrito Federal as atribuições de organizar e manter a Defensoria Pública do Distrito Federal. Brasília: Câmara dos Deputados, 2012. Disponível em: http://www.planalto.gov.br/ccivil_03/constituicao/emendas/emc/emc69.htm. Acesso em: 4 jun. 2019.

BRASIL. Emenda à Constituição n ${ }^{\circ} 74$ de 2013. Altera o art. 134 da Constituição Federal. Brasília: Câmara dos Deputados, 2013. Disponível em: http://www.planalto.gov.br/ccivil_03/constituicao/Emendas/Emc/emc74.htm. Acesso em: 4 jun. 2019. 
COMPARATIVE CONSTITUTIONS PROJECT. Informing constitutional design. [S.l]: Comparative Constitutions Project, 2019. Disponivel em: http://comparativeconstitutionsproject.org/. Acesso em: 20 set. 2019.

COX, G. W.; MCCUBBINS, M. D. The Institutional Determinants of Economic Policy Outcomes. In: HAGGARD, S.; MCCUBBINS, M. D. Presidents, Parliaments, and Policy. Cambridge: Cambridge University Press, 2001. p. 31-96.

ECKERT, S. Two spheres of regulation: Balancing social and economic goals. Regulation and Governance, [s.l], v. 12, n. 2, p. 177-191, 2017. Disponível em: https://doi.org/10.1111/rego.12137. Acesso em: 20 set. 2019.

ELGIE, R. Why Do Governments Delegate Authority to Quasi-Autonomous Agencies? The Case of Independent Administrative Authorities in France. Governance: An International Journal of Policy, Administration, and Institutions, [s.l], v. 19, n. 2, p. 207-227, 2006. Disponível em: https://doi.org/10.1111/j.1468-0491.2006.00312.x. Acesso em: 20 set. 2019.

FEREJOHN, J. E. Constitutional Review in the Global Context. Legislation and Public Policy, [s.l], v. 6, n. 49, p. 49-59, 2002. Disponível em: https://www.nyujlpp.org/wpcontent/uploads/2012/11/John-E-Ferejohn-Constitutional-Review-in-the-Global-Context.pdf. Acesso em: 20 set. 2019.

FUKUYAMA, F. What Is Governance? Governance: An International Journal of Policy, Administration, and Institutions, [s.1], v. 26, n. 3, p. 347-368, 2013. Disponível em: https://doi.org/10.1111/gove.12035. Acesso em: 20 set. 2019.

HOOGHE, L.; MARKS, G. Unraveling the Central State, but How? Types of Multi-level Governance. American Political Science Review, [s.l.], v. 97, n. 2, p. 233-243, May 2003. Disponível em: http://garymarks.web.unc.edu/files/2016/09/hooghe.marks_.unravelingcentralstate.apsr_.2003.p df. Acesso em: 20 set. 2019.

JENSEN, M. C.; MECKLING, W. H. Teoria da Firma: Comportamento dos Administradores, Custos de Agência e Estrutura de Propriedade. Revista de Administração de Empresas, São Paulo, v. 48, n. 2, p. 87-125, 2008. Disponível em:

http://www.scielo.br/pdf/rae/v48n2/v48n2a13.pdf. Acesso em: 20 set. 2019.

KNIGHT, J. Institutionalizing Constitutional Interpretation. In: FEREJOHN, J.; RAKOVE, J. N.; RILEY, J. Constitutional Culture and Democratic Rule. Cambridge: Cambridge University Press, 2001. p. 361-391.

LIJPHART, A. The Two-Dimensional Conceptual Map of Democracy. In: LIJPHART, A. Patterns of Democracy. New Haven: Yale University Press, 1999. p. 243-257.

LUPIA, A.; MCCUBBINS, M.. Representation or abdication? How citizens use institutions to help delegation succeed. European Journal of Political Research, [s.l], v. 37, p. 291-307, 2000. Disponível em: https://link.springer.com/article/10.1023/A:1007068904236. Acesso em: 20 set. 2019.

MOSHER, F. C. Democracy and the Public Service. New York: Oxford University Press, 1968. 
NEGRETTO, G. L. Toward a Theory of Formal Constitutional Change: mechanisms of constitutional adaptation in Latin America. In: NOLTE, D.; SCHILLING-VACAFLOR, A. New Constitutionalism in Latin America: promises and practices. Farnham: Ashgate Publishing, 2012. p. 51-72.

NEGRETTO, G. L. A Two-Level Theory of Constitutional Choice. In: NEGRETTO, G. L. Making Constitutions: presidents, parties, and institutional choice in Latin America. Cambridge: Cambridge University Press, 2013. p. 43-70.

OVERMAN, S. Autonomous Agencies, Happy Citizens? Challenging the Satisfaction Claim. Governance: an International Journal of Policy, Administration, and Institutions, [s.l], v. 30, n. 2, p. 211-227, 2016. Disponível em: https://doi.org/10.1111/gove.12207. Acesso em: 20 set. 2019.

PETERS, B. G.; PIERRE, J. Governance without Government? Rethinking Public Administration. Journal of Public Administration Research and Theory, [s.l], v. 8, n. 2, p. 223-243, Apr. 1998. Disponível em: https://doi.org/10.1093/oxfordjournals.jpart.a024379. Acesso em: 20 set. 2019.

PETERS, B. G.; PIERRE, J. Politicization of the civil service: concepts, causes, consequences. In: PETERS, B. G.; PIERRE, J. Politicization of the Civil Service in Comparative Perspective: the quest for control. London: Routledge, 2004. p. 1-13.

RODRIGUES, T. C. M. A reforma política pelo judiciário: notas sobre a judicialização da política na Nova República. Revista Brasileira de Ciência Política, Brasília, n. 28, p. 123-160, 2019. Disponível em: http://dx.doi.org/10.1590/0103-335220192805. Acesso em: 20 set. 2019.

ROSE-ACKERMAN, S. Controling Political Power. In: ROSE-ACKERMAN, S. Corruption and Government: causes, consequences, and reform. Cambridge: Cambridge University Press, 1999. p. 143-174.

SWEET, A. S.; THATCHER, M. Theory and Practice of Delegation to NonMajoritarian Institutions. West European Politics, [s.l], v. 25, n. 1, p. 1-22, 2002. Disponível em: https://doi.org/10.1080/713601583. Acesso em: 20 set. 2019.

THATCHER, M. Regulation after delegation: independent regulatory agencies in Europe. Journal of European Public Policy, [s.l.], v. 9, n. 6, p. 954-972, 2002. Disponível em: https://doi.org/10.1080/1350176022000046445. Acesso em: 20 set. 2019.

TOMIC, S. Legal independence vs. leaders' reputation: exploring drivers of ethics commissions' conduct in new democracies. Public Administration, [s.l.], v. 96, n. 3, p. 1-17, 2018. Disposnível em: https://doi.org/10.1111/padm.12411. Acesso em: 20 set. 2019.

VAN THIEL, S.; YESILKAGIT, K. Good Neighbours or Distant Friends? Public Management Review, [s.l.], v. 13, n. 6, p. 783-802, 2011. Disponível em: https://doi.org/10.1080/14719037.2010.539111. Acesso em: 20 set. 2019.

WEINGAST, B. R. The congressional-bureaucratic system: a principal agent perspective (with applications to the SEC). Public Choice, New York, v. 44, n.1, p. 147-191, 1984. Disponível em: https://doi.org/10.1007/BF00124821. Acesso em: 20 set. 2019.

Artigo recebido em: 2019-09-07

Artigo reapresentado em: 2019-09-19

Artigo aceito para publicação em: 2020-01-14 